\title{
Virtual screening of co-formers for ketoprofen co-crystallization and the molecular properties of the co-crystal
}

\author{
S. Siswandi ${ }^{1,2}$, Taofik Rusdiana ${ }^{1}$, Jutti Levita ${ }^{3 *}$ \\ ${ }^{1}$ Department of Pharmaceutics and Formulation Technology Faculty of Pharmacy, Universitas Padjadjaran Jl. Raya Bandung-Sumedang km.21 Jatinangor \\ Sumedang, Indonesia. ${ }^{2}$ Indonesian Airforce Pharmaceutical Institution Jl.Abdurachman Saleh, Lanud Husein Sastranegara, Bandung, Indonesia. \\ ${ }^{3}$ Department of Pharmaceutical Analysis and Medicinal Chemistry Faculty of Pharmacy, Universitas Padjadjaran Jl. Raya Bandung-Sumedang km.21 \\ Jatinangor Sumedang, Indonesia.
}

\section{ARTICLE INFO}

\section{Article history:}

Received on: 02/02/2015

Revised on: 23/02/2015

Accepted on: 17/03/2015

Available online: 27/06/2015

\section{Key words:}

Anti-inflammatory agent; cocrystal; co-former; ketoprofen; molecular docking; saccharin.

\begin{abstract}
Ketoprofen or [2-(3-benzoylphenyl)propionic acid] is a nonsteroidal antiinflammatory and analgesic agent. The positive qualities of ketoprofen are based on optimal physicochemical and structural characteristics, its ability to penetrate into and accumulate in the inflammation centers and compatibility with other classes of drugs. This compound is practically insoluble in water, therefore as most of NSAID drugs, it is categorized as Biopharmaceutics Classification System (BCS) class II. A widely used to enhance the solubility of poorly water soluble drugs is co-crystallization. A co-crystal is a multi-component crystal which involves non-covalent interactions between API and its co-formers. In this work, we developed virtual screening of co-formers for ketoprofen by employing molecular docking method. AutoDock was used for docking. Parameters observed were type and energy (Ei) of interaction. The work was continued by co-crystallization process and solubility assay of the mixtures according to Higuchi and Connor method using UV spectrophotometer. Based on molecular docking, the best co-former is saccharin $(\mathrm{Ei}=-3.14 \mathrm{kcal} / \mathrm{mol})$. The docking result fits the solubility assay of the ketoprofen-saccharin co-crystal $(300.62 \mu \mathrm{g} / \mathrm{mL}$ in water or $256.54 \%$ increasing of solubility compared to ketoprofen). Ketoprofen co-crystal shows better curve (90.15\% in 60 minutes) than ketoprofen (78.87\% in 60 minutes). Co-crystallization of ketoprofen with saccharin increases the dissolution profile of ketoprofen.
\end{abstract}

\section{INTRODUCTION}

Ketoprofen (Fig.1) or [2-(3-benzoylphenyl)propionic acid] is a nonsteroidal antiinflammatory and analgesic agent. The positive qualities of ketoprofen are based on optimal physicochemical and structural characteristics, its ability to penetrate into and accumulate in the inflammation centers and compatibility with other classes of drugs (Khormosh, 2009). Ketoprofen is soluble in ethanol, chloroform, and ether. It is practically insoluble in water, therefore as most of NSAID drugs, this compound is categorized as Biopharmaceutics Classification System (BCS) class II, i.e. drugs with low solubility and high permeability character (Hussain, 2002). Various techniques have

* Corresponding Author

Jutti Levita, e-mail: jutti.levita@unpad.ac.id

Mobile: +628156043663, Office: +62227796200 been widely used to enhance the solubility of poorly water soluble drugs; co-crystallization is one amongst them.<smiles>CC(C(=O)O)c1cccc(C(=O)c2ccccc2)c1</smiles>

Fig.1 2D structure of ketoprofen ID 3693

A co-crystal is a multi-component crystal which all components are solid at room temperature in a stoichiometric ratio and it involves non-covalent interactions such as hydrogen bonds, van-der Waals bonds, ionic bonds in a crystal lattice (Shan, 2008; Patel, 2012). The selection of co-formers is based on their ability to form reversible or non-covalent interaction with the API. 
Both API and co-former should contain hydrogen bond donors (HBDs) or acceptors (HBAs), e.g. ether, thioether, alcohol, ketone, thioketone, ester, thioester, carboxylic acid, amide, primary and secondary amines, etc (Vinesha, 2013). Other interactions involved in the formation of co-crystals are Van der Waals force, pi-pi $(\pi-\pi)$ interaction, aromatic stacking, and halogen bonding (He, 2008).

\section{MATERIALS AND METHODS}

\section{Hardware and programs}

Personal computer Intel $^{\circledR}$ Celeron ${ }^{\circledR}$ CPU 1007U @ $1.50 \mathrm{GHz}$ (2 CPUs), $1.5 \mathrm{GHz}, 2048 \mathrm{MB}$ RAM, BIOS: InsydeH2O Version 03.72.23V2.17, $200 \mathrm{~GB}$, was employed in this work. Programs used were ChemOffice 2004 (trial version), Portable_Hyperchem_8.0.7, AutoDock 4.2.3, OpenBabelGUI 2.2.3.

\section{Molecular modelling}

2D structures of ketoprofen (ChemSpider ID: 3693) and its co-formers in .mol format were downloaded from www.chemspider.com. All molecules were geometry optimized using molecular mechanics method in Portable_Hyperchem_8.0. and calculated their QSAR properties using the same program.

\section{Molecular docking}

All .mol files of the molecules were converted into .pdb files by employing OpenBabelGUI 2.2.3. The files then were opened in AutoDock 4.2.3 and converted into .pdbq files by adding polar hydrogen and Kollman charges. The . $p d b q$ files were converted into .pdbqt by calculating their torsion angles and were ready to be used for docking. The dimension of grid box was set to 40x40x40 $\AA^{3}$ and other parameters were set to default. Docking was repeated 10 times for each co-former. Parameters observed were type and energy (Ei) of interactions.

\section{Solubility assay}

Instruments used were mechanical agitator (Kotterman 4010), Shimadzu UV 1700 spectrophotometer, and chemical glasswares. Solubility assay was carried out according to Higuchi and Connor method on ketoprofen and all co-crystals formed. An accurately weighed $100 \mathrm{mg}$ of ketoprofen was dissolved to saturation in water and was shaken vigorously using mechanical agitator for $24 \mathrm{~h} 120 \mathrm{rpm}$. The mixture was filtered and passed through milipore membrane $\varnothing 25 \mu \mathrm{m}$. Filtrate was measured at 250-260 nm.

\section{Dissolution test}

The best co-former according to virtual screening and solubility assay is equimol mixed and ground with ketoprofen, and $5 \mathrm{~mL}$ of methanol is added drop wise to the mixture.

The crystal formed is kept at room temperature $\left(27^{\circ} \mathrm{C}\right)$ for $24 \mathrm{~h}$. Dissolution test is performed to both ketoprofen and ketoprofen co-crystal at 10 minutes interval for $1 \mathrm{~h}$.

\section{RESULTS AND DISCUSSION}

The molecule of ketoprofen contains two aromatic rings as well as $1 \mathrm{HBD}$ (hydrogen atom of the carboxylate) and 3 HBAs (oxygen atoms of the carbonyl and carboxylate), hence it is possible to form co-crystals with certain co-formers. Co-formers chosen in this work were benzoic acid, fumaric acid, malonic acid, citric acid, stearic acid, succinic acid, saccharin, and methyl paraben. The result of virtual screening of co-formers using molecular docking is showed in Table 1.

Table 1 shows that benzoic acid, citric acid, and saccharin are the only co-formers able to form non-covalent interactions with ketoprofen. Benzoic acid $(\mathrm{Ei}=-2.13 \mathrm{kcal} / \mathrm{mol}$ ) interacts with ketoprofen via $\pi-\pi$ interaction (or aromatic stacking) (Fig.2b), while citric acid $(-0.35 \mathrm{kcal} / \mathrm{mol})$ forms one hydrogen bond with ketoprofen (Fig.2a). The best interaction is showed by saccharin $(\mathrm{Ei}=-3.14 \mathrm{kcal} / \mathrm{mol})$ which forms two aromatic stackings and one hydrogen bond (hydrogen atom of saccharin's nitrogen at thiazole ring is a HBD to oxygen atom of ketoprofen's carbonyl) (Fig. 2c).

Mixtures of ketoprofen with the co-formers were tested for their solubilities and compared with ketoprofen itself. Results could be seen in Table 2 .

Based on solubility assay carried out using Higuchi and Connor method, ketoprofen is slightly soluble in water (117.18 $\mu \mathrm{g} / \mathrm{mL})$. By mixing it with citric acid, the solubility increases $142.67 \% \quad(167.18 \mu \mathrm{g} / \mathrm{mL})$, whereas with benzoic acid and saccharin the increasing of solubility are $162.00 \%(189.84 \mu \mathrm{g} / \mathrm{mL})$ and $256.54 \%(300.62 \mu \mathrm{g} / \mathrm{mL})$, respectively. The interactions of ketoprofen with citric acid, benzoic acid, and saccharin could be proposed and seen in Fig.2.

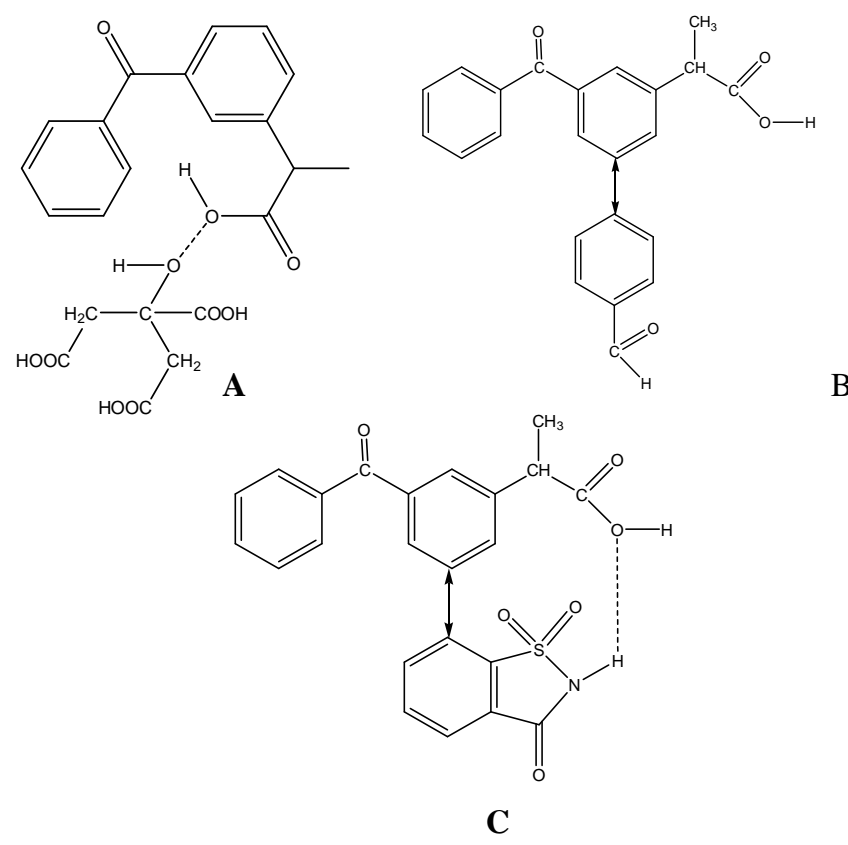

Fig. 2: Proposed interactions of ketoprofen-citric acid (a), ketoprofen-benzoic acid (b), and ketoprofen-saccharin (c), based on docking result. 
Table 1. Virtual screening of co-formers using molecular docking

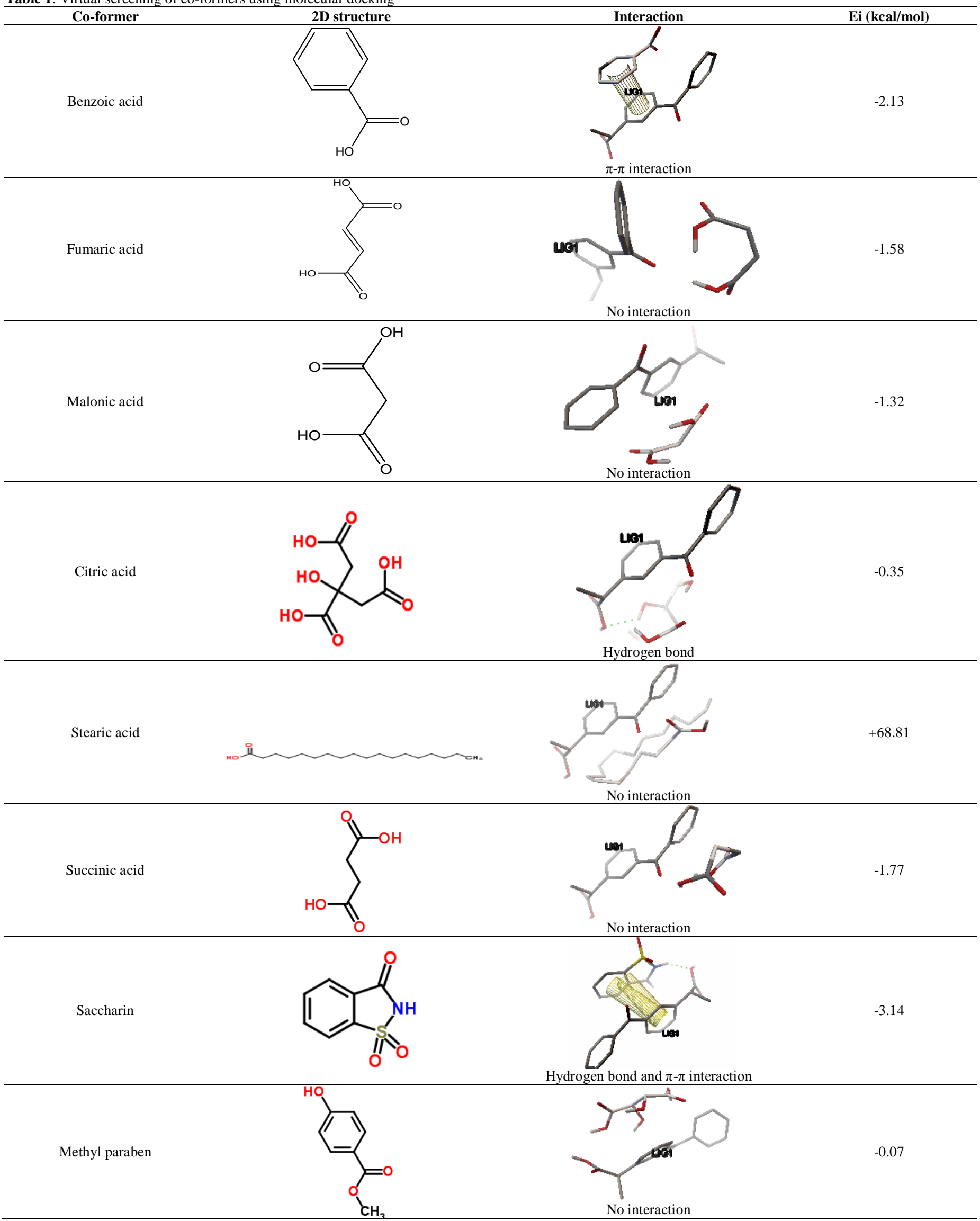



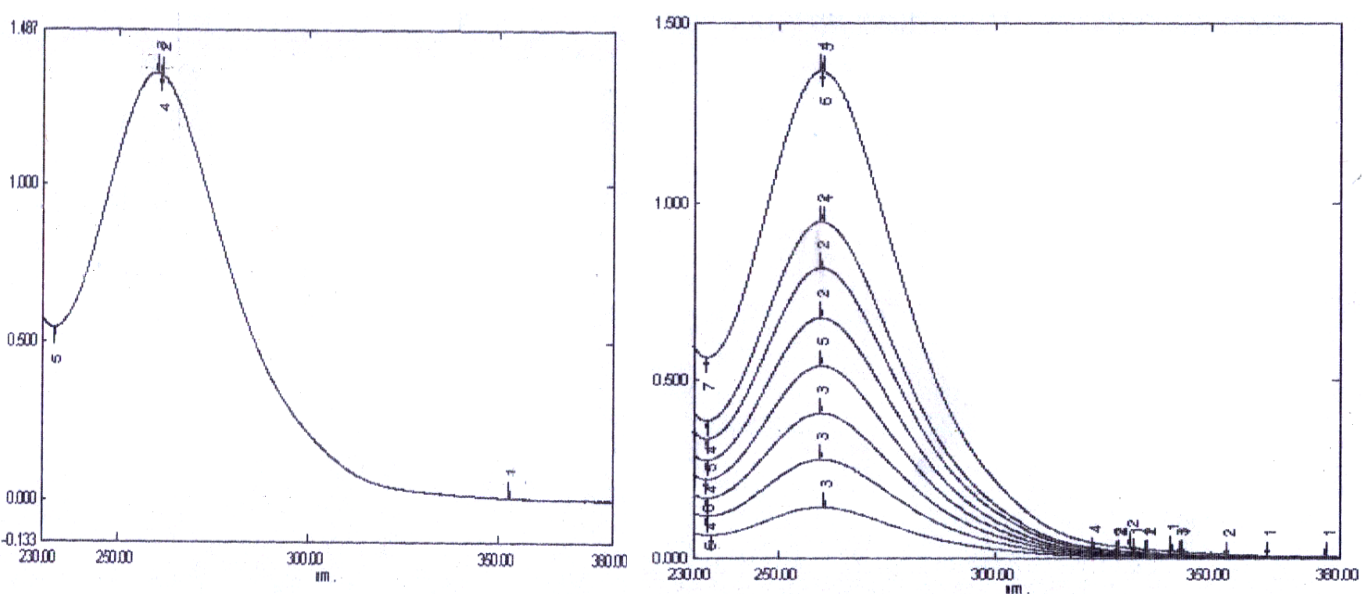

Fig. 3: UV spectrum of ketoprofen $20 \mathrm{ppm}$ (a) and overlay UV spectra of various concentration of ketoprofen (b).

Table 2: Solubility assay.

\begin{tabular}{cc}
\hline Compound & Solubility in water $(\boldsymbol{\mu g} / \mathbf{m L})$ \\
\hline Ketoprofen & 117.18 \\
Ketoprofen-citric acid & 167.18 \\
Ketoprofen-benzoic acid & 189.84 \\
Ketoprofen-saccharin & 300.62 \\
Ketoprofen-stearic acid & 28.43 \\
Ketoprofen-succinic acid & 28.75 \\
Ketoprofen-fumaric acid & 42.65 \\
\hline
\end{tabular}

Table 3: Dissolution test.

\begin{tabular}{ccc}
\hline Time (minute) & $\begin{array}{c}\text { Ketoprofen co-crystal } \\
(\boldsymbol{\%})\end{array}$ & Ketoprofen (\%) \\
\hline 0 & 0 & 0 \\
5 & 38.84 & 31.23 \\
10 & 47.20 & 41.73 \\
15 & 56.92 & 51.25 \\
30 & 72.77 & 62.27 \\
45 & 82.60 & 67.89 \\
60 & 90.15 & 77.87 \\
\hline
\end{tabular}

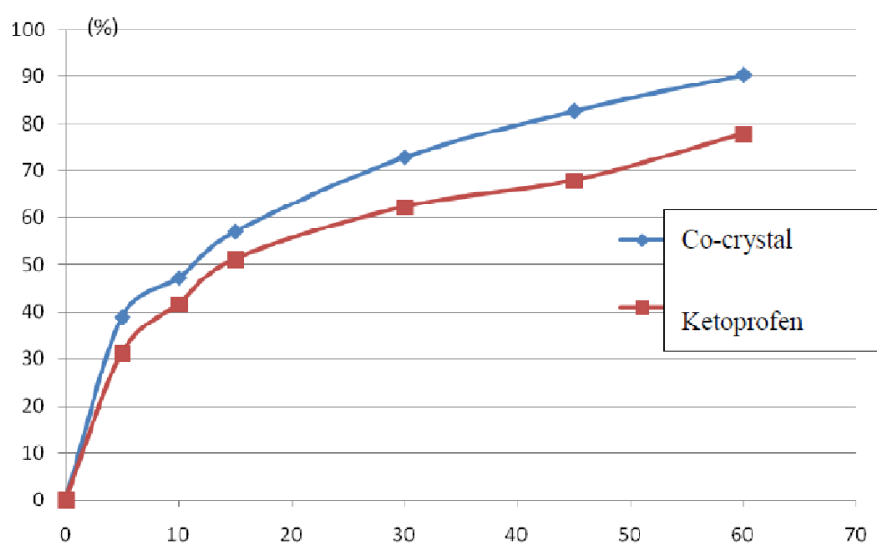

Fig. 4: Dissolution profile of ketoprofen (red) and the co-crystal (blue).

The best co-former according to virtual screening and solubility assay, that is saccharine, was further tested for its dissolution profile in water. Fig.3 shows the ultraviolet spectrum of ketoprofen. The maxima of ketoprofen is observed at $259 \mathrm{~nm}$, which fits Woodward-Fieser rules for aromatic compounds containing carbonyl attached to the ring (base value for parent chromophore is $246 \mathrm{~nm}$ ).

Other ring attached to the carbonyl in ketoprofen molecule (Fig.1) adds increments, thus shifts the maxima to longer wavelength.

Dissolution profile is showed in Table 3 and Fig.4. Ketoprofen co-crystal shows better curve (90.15\% in 60 minutes) than ketoprofen (78.87\% in 60 minutes).

Co-crystallization of ketoprofen with saccharin increases its solubility and dissolution profile due to aromatic stacking and hydrogen bond interaction of both molecules.

\section{CONCLUSION}

The best co-former is saccharin $(\mathrm{Ei}=-3.14 \mathrm{kcal} / \mathrm{mol})$. It forms two aromatic stackings and one hydrogen bond with ketoprofen. The docking result fits the solubility assay of ketoprofen-saccharin co-crystal $(300.62 \mu \mathrm{g} / \mathrm{mL}$ in water or $256.54 \%$ increasing of solubility compared to ketoprofen). Cocrystallization of ketoprofen with saccharin increases the dissolution profile of ketoprofen.

\section{REFERENCES}

Hussain, A. 2002. Biopharmaceutics Classification System (BCS): A Regulatory Risk Management Tool, FDA.

He, G.W., Jacob, C., Guo, L.F., Chow, P.S., Tan, R.B.H. Screening for co-crystallization tendency: the role of intermolecular interactions, J Phys Chem B, 2008; 112: 9890-9895

Kormosh, Z., Hunkaa, I., Basel, Y. Spectrophotometric Determination of Ketoprofen and Its Application in Pharmaceutical Analysis, Acta Poloniae Pharmaceutica ñ Drug Research, 2009; 66(1): 3-9

Patel, A.R., Carlton, R.A., Needham, T.E., Chichester, C.O., Vogt, F.G., 2012, Preparation, structural analysis, and properties of tenoxicam cocrystals, International Journal of Pharmaceutics, 436: 685-706

Shan, N., Zaworotko, M.J., 2008, The role of cocrystals in pharmaceutical science, Drug Discovery Today, 13: 440-446

Vinesha, V., Sevukarajan, M., Rajalakhsmi, R., Chowdari, G.T., et al. Enhancement of Solubility of Taladafil by Cocrystal 
Approach, International Research Journal of Pharmacy, 2013; 4(4): 218-223

\section{How to cite this article:}

Siswandi, Taofik Rusdiana, Jutti Levita., Virtual screening of coformers for ketoprofen co-crystallization and the molecular properties of the co-crystal. J App Pharm Sci, 2015; 5 (06): 078082. 